Proceedings of the 11th Polish-Japanese Joint Seminar on Micro and Nano Analysis, Gniew, September 11-14, 2016

\title{
Hot Compression Test of Heat Resistant Steel
}

\author{
A. Fedoriková*, T. KvaČKaj, R. Kočiško, R. Bidulský and P. Petroušek \\ Institute of Materials, Faculty of Metallurgy, Technical University of Košice, Letná 9, 04200 Košice, Slovakia
}

This article deals with the analysis of formability of heat resistant steel type $9 \mathrm{Cr}-1 \mathrm{Mo}$ by physical laboratory simulation - hot compression test. The $9 \mathrm{Cr}-1 \mathrm{Mo}$ steel belongs to modern $9 \% \mathrm{Cr}$ tempered martensitic steel for high-temperature applications in advanced thermal power plants. The shape of the sample was defined based on numerical simulations. The laboratory simulation of forming process called physical simulation — specifically hot compression test was realized in the temperature range from 500 to $950{ }^{\circ} \mathrm{C}$ and total deformation in the range from 39 to $52 \%$. Cracks formed during hot compression test in the notches are assessed. Subsequently, the relation between the compression temperature, strain, and crack length was defined. The suitable workability corresponds to the temperature range $650-900{ }^{\circ} \mathrm{C}$, it agrees with results of numerical simulations. At a temperature of $900{ }^{\circ} \mathrm{C}$ there is marginal relative deformation without rupture $\varepsilon=39.9 \%$, which corresponds to the value according to simulations NCL criteria 0.501 .

DOI: 10.12693/APhysPolA.131.1340

PACS/topics: 81.05.Bx, 81.40.Gh, 81.40.Np, 02.70.Dh

\section{Introduction}

The improvement of thermal efficiency by increasing the operating temperature and pressure of boilers has recently led to the development of new grades of creepresistant steels [1]. Shi et al. [2] showed that modified $9-12 \%$ Cr steels improved properties of heat-resistant steels. The $9 \mathrm{Cr}-1 \mathrm{Mo}$ steel represents tempered martensitic steel with complex alloying assuring transformation, solid solution, and precipitation strengthening at elevated temperatures [2]. Mechanical properties are examined in the literature [3, 4]. It is used for thick section components of steam generators operating in the temperature range $550-650^{\circ} \mathrm{C}$. The presence of precipitated particles formed in the microstructure of $9 \mathrm{Cr}-1$ Mo steels during annealing may cause the formation of the voids during plastic deformation [5]. $9 \mathrm{Cr}-1 \mathrm{Mo}$ steel is suitable for welding, and there are several impact studies about the correlation between microstructure and conditions of welding with others materials and post-weld heat treatment $[6,7]$. Workability and fracture limit criterions have not been determined yet. Because many kinds of alloying elements exist in the steel, and the microstructure evolution is complicated during hot working, it is difficult to establish the hot working regime [2]. Workability can be defined as the degree of deformation that can be achieved in a particular metalworking process without creating undesirable condition and defects [8]. Oh et al. [9] have modified a Cockroft-Latham criterion for uniaxial stress through normalizing of maximum principal tensile stress. A normalized Cockroft-Latham criterion $(\mathrm{nCL})$ is described by Eq. (1):

$$
\int_{0}^{\bar{\varepsilon}} \frac{\sigma_{1}}{\bar{\sigma}} \mathrm{d} \bar{\varepsilon}=C_{1}
$$

where $\bar{\sigma}[\mathrm{MPa}]$ - effective stress, $C_{1}[\mathrm{MPa}]-$ material constant [10].

On the basis of the knowledge of material constant $C_{1}$ there can be characterized workability of the material [10]. Using those criteria and values we expect of fracture, but these mathematical simulations should be verified physically and thus accurately determined their value and terms of workability of the material $[11,12]$.

The aim of this paper is an evaluation of workability by physical simulation - hot compression test. The sampling shape was designed according to the results of the mathematical simulations [13-15]. Cracks formed in the notches are assessed. After the test, the relationship between the compression temperature, strain, and crack length was defined.

\section{Experimental material and methods}

The chemical composition given by Table I represents heat-resistant $9 \mathrm{Cr}-1$ Mo steel grade used for physical simulations.

TABLE I

Chemical composition of heat-resistant $9 \mathrm{Cr}-1 \mathrm{Mo}$ steel grade.

\begin{tabular}{c|c|c|c|c|c|c|c}
\hline \hline $\mathrm{C}$ & $\mathrm{Cr}$ & $\mathrm{Mo}$ & $\mathrm{W}$ & $\mathrm{Mn}$ & $\mathrm{Si}$ & $\mathrm{V}$ & $\mathrm{Ni}$ \\
\hline 0.106 & 8.85 & 0.417 & 1.864 & 0.447 & 0.298 & 0.24 & 0.136
\end{tabular}

The shape of samples was selected by numerical simulations in Deform 2D/3D. Conditions of numerical simulations were as follows: both anvils were rigid, upper anvil movement speed was $0.66 \mathrm{~mm} / \mathrm{s}$, workpiece (sample) was isotropic and plastic with $9 \mathrm{Cr}-1$ Mo material properties, used FEM mesh had 32000 elements. Used material properties in numerical simulation are from Deform $2 \mathrm{D} / 3 \mathrm{D}$ material database. The final sample shape tapered type with four axial notches has been identified as the most suitable form of the sample given the maximum value in the $\mathrm{nCL}$ criteria compared to other types of samples according to the literature [13]. In fact, for physical simulations the shape of sample was brought into line with the requirement of the testing machine, Fig. 1a,b.

Physical simulation means the laboratory test with conditions compatible with the real forming process. In 


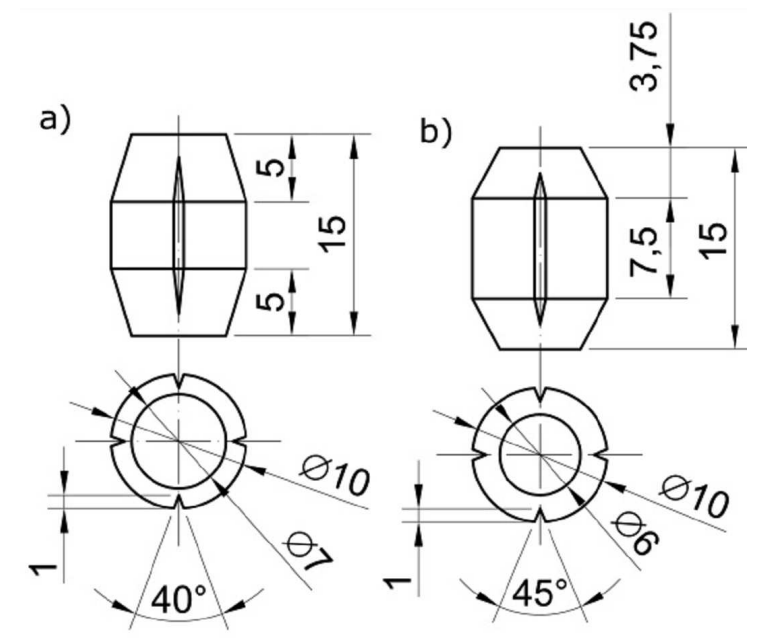

Fig. 1. Tapered sample with four axial notches, (a) used in simulations, (b) used for physical simulations.

other words, the hot compression test was realized in the temperature range $T \in\langle 500 ; 950\rangle\left[{ }^{\circ} \mathrm{C}\right]$ and total deformation was $\varepsilon \in\langle 39 ; 52\rangle[\%]$ which copy the actual processing conditions of experimental material. During the laboratory tests, the value of upper anvil moving $D_{h}[\mathrm{~mm}]$ and the force that the upper anvil acts on sample $F[\mathrm{~N}]$ were recorded. The upper anvil movement speed was consistent with movement speed from numerical simulations $(0.66 \mathrm{~mm} / \mathrm{s})$. Based on these data the following data were determined: actual height of samples at any time $h_{x}[\mathrm{~mm}]$, the actual area at which the force $F$ operates at any time $S_{x}\left[\mathrm{~mm}^{2}\right]$, the actual stress $\sigma_{\text {true }}[\mathrm{MPa}]$ and the true strain $\varphi$.

\section{Results}

During the testing, samples were deformed not ideal; there was a slope of the sample. The simulation of the actual course of deformation is shown in Fig. 2, corresponding $\mathrm{nCL}=0.504$ criterion in the value of $\varepsilon=66 \%$. These values are comparable to the nCL criterion for conditional simulation under ideal conditions.
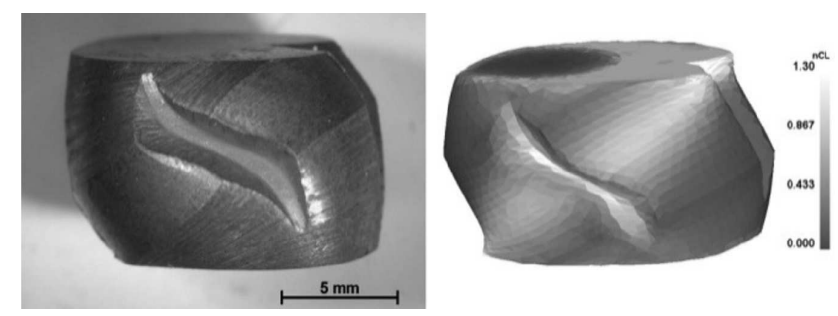

Fig. 2. Sample after hot compression test and simulation of actual course of deformation.

The highest tensile stress in notches presents in the direction of the "slant" samples. Because of the possibility of workability comparing, cracks in notches that are deformed into the shape of the letter "S" are included. For the evaluation of the experiment each crack was assessed, depending on temperature and strain. The crack lengths were measured by AxioVision Microscope software, Fig. 3.

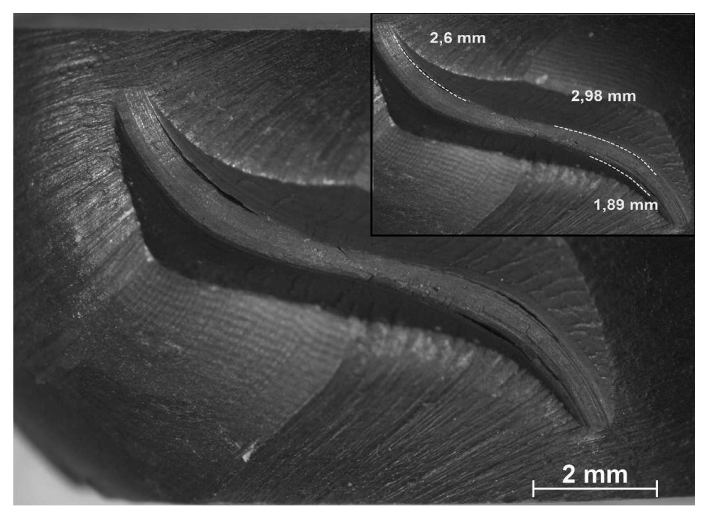

Fig. 3. Example of crack lengths measurement.

In Fig. 4 there is shown a graphical representation of the average length of cracks arising in the notch "S". Evaluation was done in two ways - mean of cracks length and sum of cracks.

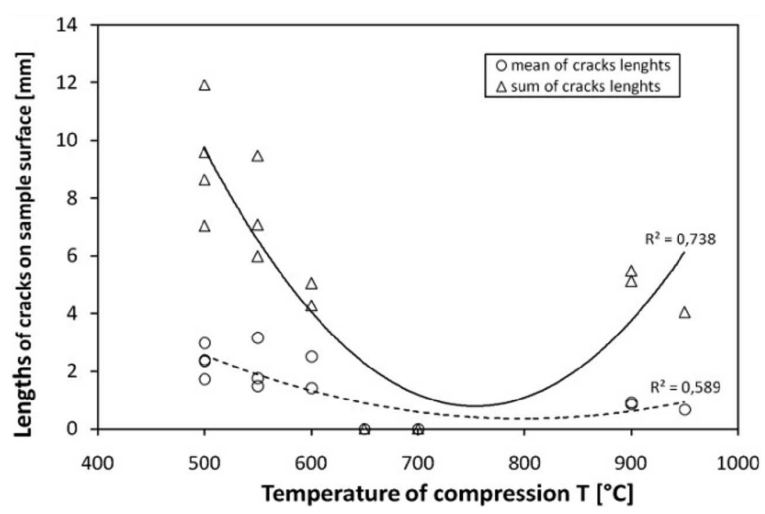

Fig. 4. Graphical evaluation of cracks lengths in notches.

Zero values are assigned to samples in which there has been no violation of integrity. The two waveforms have a similar pattern, in the temperature range of $700-900^{\circ} \mathrm{C}$ it is a local minimum, which corresponds to the assumption of the numerical simulations, since in this temperature range the $\mathrm{nCl}$ criterion has the lowest value. At $900^{\circ} \mathrm{C}$, a gradual increase in the value is visible and on the samples cracks again are observed.

To include the size of the total impact of strain on the length of the cracks there were evaluated graphs of the average of the sum of the lengths to compression temperature and strain measured during experiment. In the first case, a graph of the mean of cracks lengths depending on compression temperature and total strain is shown in Fig. 5. 


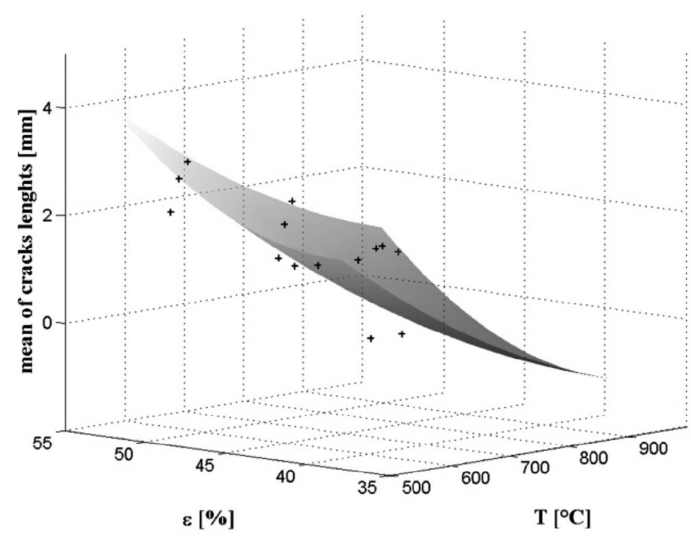

Fig. 5. Mean of cracks lengths depending on compression temperature and strain.

The dependence can be described by the following Eq. (2), parameters of empirical models were determined by the least squares method

$$
\begin{aligned}
& \text { mean }=-1.5724+7.0569 \times 10^{-6}(T-1200.3)^{2} \\
& \quad+0.0119(\varepsilon-38.3545)^{2}[\mathrm{~mm}] .
\end{aligned}
$$

The residuum (the sum of the squared residuals) for Eq. (2) is 2.8272.

Figure 6 shows the dependence of the sum of cracks lengths on compressing temperature and total strain.

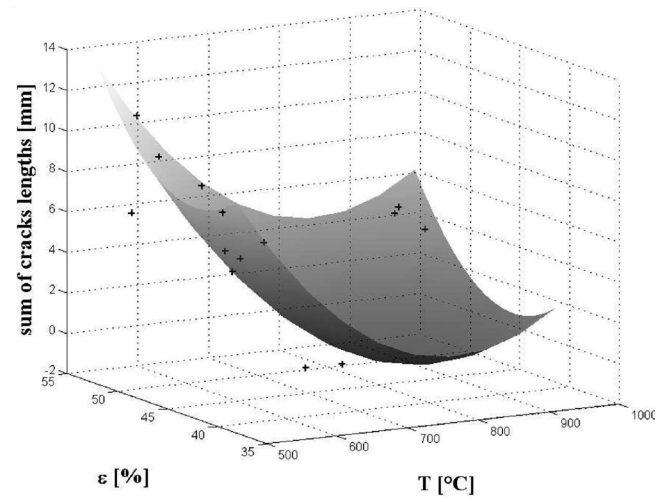

Fig. 6. Sum of cracks lengths depending on compression temperature and strain.

This dependence can be described by the following Eq. (3), parameters of empirical models were determined by the least squares method

$$
\begin{aligned}
& \text { Sum }=-0.4060+9.1925 \times 10^{-5}(T-809.3960)^{2} \\
& \quad+0.0558(\varepsilon-42.1756)^{2}[\mathrm{~mm}] .
\end{aligned}
$$

The residuum (the sum of the squared residuals) for Eq. (3) is 29.3791.

Previous Eqs. (2) and (3) are mathematical dependence of the crack length on the forming temperature and the total material strain. Based on these equations, it can be assumed what forming conditions may cause the material failure.

From both graphs, Fig. 5 and Fig. 6, there can be formulated the conclusion that with increasing temperature and increasing deformation, increases of the length of cracks are formed in the notch.

\section{Discussion}

In Fig. 7 is a graphical representation of the size of cracks on the temperature and the relative deformation. Square marked samples are those on which has been no violation of integrity.

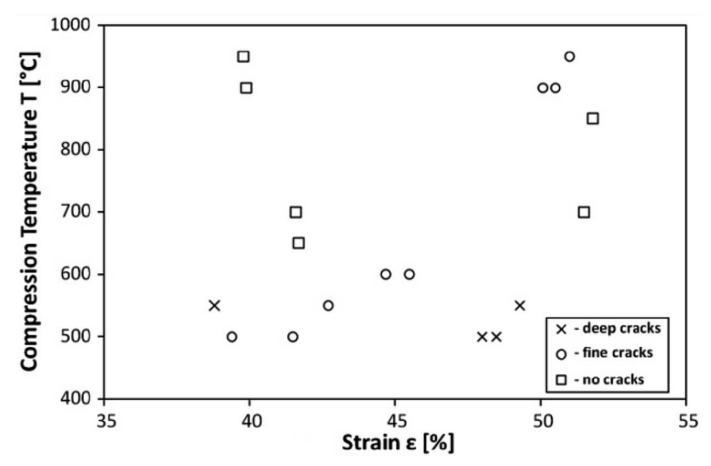

Fig. 7. The evaluation of cracks depending on the temperature $T$ and the strain $\varepsilon$.

On the round marked samples, some cracks were visible, but they were mostly superficial and delicate. Cross marks show the sample, on which there were seen large and deep cracks. The graph shows the not suitable area for the forming of material, where the strain is greater than $47 \%$ along a temperature below $650^{\circ} \mathrm{C}$. In the temperature range from 560 to $800^{\circ} \mathrm{C}$ and at deformation higher than $51 \%$, it is seen that this area can be considered as a suitable temperature range for forming the steel $9 \mathrm{Cr}-1 \mathrm{Mo}$. The integrity of materials without breaking was observed.

It is possible to continue the further experiments because the proportions of selected sample at the interface between the tool and the sample were shown to be not very satisfactory. The sample is actually deformed at the same bevel angle, the expected course of deformation has not been achieved. The flatness of the upper and lower base of the sample after compression maintain, so we can eliminate misalignment dies during the test. It can be assumed that if a greater content of the base area and the sample was created, the problem in the test could be removed. However, samples dimensions should be designed according to the requirements of the device and also take into account the dimensions of dies and maintain the required ratio between the area and the base area dies samples.

Given the course of a hot compression test, it was not possible to determine strain into first violations. The simulation, which has been calculated and adapted to 
the actual behavior of the sample during the test, is not indicative of the value of the actual deformations.

\section{Conclusions}

- Based on experimental test results it can be said that the increase of compression temperature causes decrease of tensile strength of the material.

- The more appropriate parameter for assessing the dependence of crack length from temperature and strain is the sum of all lengths incurred at the sample.

- The sum of lengths of cracks in the sample depending on temperature and strain with increasing temperature decreases to a certain point, which amounts to a minimum and then increases again.

- The suitable workability corresponds to the temperature range $650-900^{\circ} \mathrm{C}$, it agrees with results of numerical simulations.

- At a temperature of $900^{\circ} \mathrm{C}$ there is marginal relative deformation without rupture $\varepsilon=39.9 \%$, which corresponds to the value according to simulations NCL criteria 0.501 .

- It is possible to continue to develop the size and shape of the sample to avoid the bevels during the test.

- Changes of microstructure dependence on temperature and total strain requires further investigations.

\section{Acknowledgments}

This work was financially supported by VEGA $1 / 0325 / 14$.

\section{References}

[1] J.C. Vaillant, B. Vandenberghe, B. Hahn, H. Heuser, C. Jochum, Int. J. Pres. Ves. Pip. 85, 38 (2008).

[2] R. Shi, Z. Liu, J. Iron Steel. Res. Int. 18, 53 (2011).

[3] A. Zieliński, G. Golanski, M. Sroka, Kovove Mater. 54, 1 (2016).

[4] P.J. Ennis, A. Zielinska-Lipiec, A. CzyrskaFilemonowicz, Mater. Sci. Tech. Ser. 16, 10 (2000).

[5] J. Blach, L. Falat, P. Švec, Eng. Fail. Anal. 16, 1397 (2009).

[6] L. Falat, L. Čiripová, J. Kepič, J. Buršík, I. Podstranská, Eng. Fail. Anal. 40, 141 (2014).

[7] L. Falat, A. Výrostková, M. Svoboda, O. Milkovič, Kovove Mater. 49, 417 (2011).

[8] B.P.P.A. Gouveia, J.M.C. Rodrigues, P.A.F. Martins, Int. J. Mech. Sci. 38, 361(1996).

[9] S.I. Oh, C.C. Chen, S. Kobayashi, J. Eng. Ind. ASME 101, 36 (1979).

[10] T. Kvačkaj, R. Kočiško, J. Tiža, J. Bidulská, A. Kováčová, R. Bidulský, J. Bacsó, M. Vlado, Arch. Metall. 58, 407 (2013).

[11] L. Tan, X. Ren, T.R. Allen, Corros. Sci. 52, 1520 (2010).

[12] C.C. Huang, J.H. Cheng, Int. J. Mech. Sci. 45, 1123 (2005).

[13] A. Fedoriková, T. Kvačkaj, R. Kočiško, R. Bidulský, P. Petroušek, J. Bidulská, L. Domcová, Acta. Metall. Slov. 22, 102 (2016).

[14] P. Petroušek, T. Kvačkaj, R. Kočiško, R. Bidulský, J. Bidulská, A. Fedoriková, T. Hlava, Acta. Metall. Slov. 21, 176 (2015).

[15] R. Kočiško, R. Bidulský, L. Dragošek, M. Škrobian, Acta Metall. Slov. 20, 302 (2014). 